Pediat. Res. 9: 600-604 (1975)

Glucose

hypoglycemia

glycogen

neonate

hyperglycemia

\title{
Glucose Regulation by Isolated Near Term Fetal Monkey Liver
}

\author{
WALTER H. GLINSMANN, ${ }^{32}$ HOWARD J. EISEN, ALMORRIS LYNCH, AND RONALD A. CHEZ \\ Section on Physiological Controls, Laboratory of Biomedical Sciences, and Pregnancy Research Branch, National \\ Institute of Child Health and Human Development, National Institutes of Health, Bethesda, Maryland, USA
}

\begin{abstract}
Extract
Near term fetal monkey livers were perfused with a closed recirculating system and a defined perfusion medium. Livers from normal fetal animals were able to release glucose rapidly into the perfusate when they were exposed to glucagon, cyclic AMP, or an aglycemic perfusate, but they did not remove glucose rapidly from the perfusate, synthesize glycogen, or activate liver glycogen synthetase in response to hyperglycemia (Figs. 1, 2, and 3; Table 1). Insulin decreased glucose mobilization in response to aglycemia, but did not stimulate glucose uptake during hyperglycemia; insulin activated glycogen synthetase (Table 1; Figs. 1 and 3 ). Livers from fetuses of streptozotocin-treated mothers and livers from 2-week-old neonates released more glucose into the perfusate in response to aglycemia then did livers from normal fetal monkeys (Fig. 4). These observations support the possibility that neonatal monkey liver is capable of rapidly mobilizing glucose during periods of hypoglycemia but is unable to take up glucose and store glycogen rapidly during periods of hyperglycemia.
\end{abstract}

\section{Speculation}

Incomplete development of glycogen synthetic mechanisms in early postnatal life may contribute to decreased liver glycogen reserves. These decreased reserves may then be inadequate for maintaining normoglycemia during periods of increased glucose uptake or utilization by peripheral tissue.

One of the primary functions for liver is to maintain blood glucose levels. This is achieved by changes in gluconeogenic glucose production and by alterations in glycogen turnover. In the present study we were interested in the ability of perinatal monkey liver to regulate acutely circulating glucose concentration. We focused on alterations in glycogen metabolism, since rapid changes in hepatic glucose uptake and release are largely mediated by corresponding changes in glycogen synthesis and degradation (16, $17,19,23)$.

During early human neonatal life, blood sugar regulation is incompletely developed and hypoglycemia may occur (28). This is particularly frequent in infants from diabetic mothers requiring exogenous insulin $(6,21,22,24,25)$. One factor which could cause or contribute to neonatal hypoglycemia is immaturity of glucoregulatory responses of late fetal and early neonatal liver. To examine these responses in nonhuman primates, we have used an isolated liver perfusion system in which the variables of circulating glucose and hormone concentrations can be independently controlled.

In the adult mammal, liver glycogen turnover is regulated hormonally via alterations in cyclic AMP metabolism (11) and directly by glucose concentration via a cyclic AMP-independent mechanism $(5,18,19)$. Both processes result in coordinated changes in the activities of the rate-limiting glycogen-synthetic enzyme glycogen synthetase and the degradative enzyme phosphorylase $(5,7,11,18,19)$. Studies with term fetal rat liver in culture
(9, 10, 27, 29) support the possibility that at birth hormonal regulation of glycogen metabolism is competent, but direct glucose regulation of glycogen synthesis has not developed.

In humans, development of rapid glucose and glycogen mobilizing responses precedes birth $(1,13,26)$, and liver glycogen levels, high at birth, decline rapidly during the first few hours of life (3, 28). Idiopathic neonatal hypoglycemia does not appear to be associated with impaired glycogenolytic mechanisms since it usually occurs when liver glycogen stores are depleted $(3,28)$. Consequently, we considered that incomplete development of glycogen synthetic mechanisms in early postnatal life might contribute to decreased liver glycogen reserves and that these inadequate reserves are incapable of maintaining normoglycemia.

We now provide additional support for this possibility based on studies with isolated perfused rhesus monkey livers from near term fetuses of normal mothers and mothers with streptozotocin-induced glucose intolerance, and from normal monkey neonates. In all three groups, hepatic glucose removal rates were low in the presence of high glucose concentrations in the perfusion solution. Changes in circulating glucose concentration did not modify glycogen synthetase activity, but in all instances liver glucose was released in response to hypoglycemia. Direct effects of exogenous glucagon and insulin on hepatic glucose output and glycogen cycle enzyme activity were demonstrated in the near term fetus group.

\section{METHODS}

\section{ANIMALS}

Pregnant Macaca mulatta monkeys with accurately timed gestation ( \pm 1 day) were obtained from the National Institutes of Health Primate Colony between gestation days 143 and 152 (term equals 164 days). After a 16-hr fast, the animals were tranquilized with ketamine $\cdot \mathrm{HCl}$ before halothante-nitrous oxide-oxygen anesthesia administered via an endotracheal tube.

The fetal monkeys used in the present experiments were also used for in utero studies before delivery. The effects of EDTA infusions on fetal serum ionized calcium and parathormone levels were examined during the hour preceding delivery (12). In all experiments, serum ionized calcium, plasma glucose levels, and fetal blood gas and $\mathrm{pH}$ were normal for at least $30 \mathrm{~min}$ before delivery by hysterotomy.

In some cases, maternal glucose intolerance was induced by the intravenous administration of streptozotocin before fertilization. The details of this approach have been published (22). The maternal glucose intolerance was characterized by moderate to severe glucosuria and 3.2-5.4-fold increases in intravenous glucose disappearance half-times relative to controls.

In other experiments, we used normal 11- and 13-day-old monkeys that had been delivered spontaneously at term and had remained with their mothers. These animals, used without prior experimentation, were anesthetized with sodium pentobarbital given intravenously before perfusion. 


\section{LIVER PERFUSION}

A recirculating in situ perfusion system, previously used for studying hepatic glucose regulation in the rat $(5,11,17,18,23)$, was used for studies with fetal and newborn monkeys. The perfusion apparatus consisted of 500-ml silicone-coated film oxygenators and diaphragm pumps enclosed within a temperaturecontrolled cabinet maintained at $37^{\circ}$. Constant gassing of the perfusate with humidified and prewarmed $95 \%$ oxygen $-5 \% \mathrm{CO}_{2}$ maintained oxygenation and buffering. The perfusate, $4 \mathrm{ml} / \mathrm{g}$ liver, consisted of $32 \%$ (packed cell volume) saline-washed sheep erythrocytes, $3 \%$ bovine serum albumin, and Krebs-Ringer bicarbonate buffer $\left(\mathrm{pH} 7.4,37^{\circ}\right)$. It was circulated to the livers by a syringe-driven diaphragm pump ( 10 or $20 \mathrm{ml} /$ cycle). Perfusate $\mathrm{pH}$ was monitored by a Radiometer model BMSI blood micro system and maintained between 7.39 and 7.42 by the addition of $6.5 \%$ $\mathrm{NaHCO}_{3}$. Plasma sodium concentration was increased less than 3 $\mathrm{mEq} /$ liter by these additions.

Within 1 min after delivery, a cannula was rapidly inserted into the abdominal umbilical vein and fetal blood was washed from the liver with $25 \mathrm{ml}$ starting perfusate. A cannula placed through the right atrium and into the inferior vena cava was tied in place with the tip 5-7 $\mathrm{mm}$ above the diaphragm. The inferior cava above the right renal vein, the hepatic artery, and vessels to the gut were clamped to establish a closed recirculating perfusion. The outflow cannula return to the reservoir was positioned at a level $20 \mathrm{~cm}$ below the liver to maintain constant negative pressure. The inferior lobes of the liver were dissected free of intestine and a sheet of plastic film was placed between the liver and the gut. Flow was adjusted to $1.8-2.2 \mathrm{ml} / \mathrm{g}$ liver $/ \mathrm{min}$ to provide a slight expansion of the liver during the filling cycle. The perfusion in the older neonate was by way of the portal vein as with the adult rat. In all instances the common bile duct was dissected free and transected to prevent biliary stasis.

Sampling of the liver was accomplished by placing a tie around the tip of one of the lobes and introducing a tamponade after surgical removal of the tip. Perfusate glucose and potassium concentrations were determined by sampling from the perfusate reservoirs. Glucose uptake was estimated from the net change in perfusate glucose over time.

Porcine glucagon-free insulin and crystalline glucagon were kindly donated by Eli Lilly Research Laboratory. Both were dissolved at $1 \mathrm{mg} / \mathrm{ml}$ in $1 \mathrm{mM} \mathrm{HCl}$ and then diluted immediately before use with saline containing $0.2 \%$ albumin. Glucagon and insulin were added to achieve a concentration of $10^{-8} \mathrm{M}$. Insulin was then infused at a constant rate of $10^{-9} \mathrm{~mol} / \mathrm{hr}$. Cyclic AMP, from Boehringer-Mannheim, was dissolved in saline, neutralized, and added to the perfusate to achieve a concentration of $10^{-3} \mathrm{M}$. Glucose, insulin, glucagon, or cyclic AMP was added to the perfusate, as indicated in individual experiments. The effects of hypoglycemia were examined by switching flow to a second fiask containing glucose-free perfusate. A washout with $25 \mathrm{ml}$ of this perfusate preceded connection of the caval outflow cannula to the second flask.

\section{ASSAYS}

Liver glycogen concentration (ratio of glucose weight to tissue weight) (23), activities of glycogen synthetase and phosphorylase $(10,29)$, and perfusate glucose concentrations (16) were assayed as described previously. Tissue samples were ischemic for less than 4 $\mathrm{sec}$ before freezing between liquid nitrogen-chilled aluminum blocks. They were maintained in liquid nitrogen until assay. A unit of synthetase is $1 \mu \mathrm{mol}\left[{ }^{14} \mathrm{C}\right]$ glucose incorporated into glycogen from UDP- $\left[{ }^{14} \mathrm{C}\right]$ glucose $/ \mathrm{min}$ at $30^{\circ}$. A phosphorylase unit is 1 $\mu \mathrm{mol}\left[{ }^{14} \mathrm{C}\right]$ glucose incorporated into glycogen from $\left[{ }^{14} \mathrm{C}\right]$ glucose 1-phosphate/min at $37^{\circ}$. Concentrations of $4.5 \mathrm{mM}$ UDP-glucose and $45 \mathrm{mM}$ glucose 1-phosphate were used in the respective assays. Total glycogen synthetase was measured by the addition of $5 \mathrm{mM}$ glucose 6-phosphate, and percentage of the active form was then calculated as the ratio of activity without glucose 6-phosphate to activity with glucose 6-phosphate $\times 100$. Tissue homogenates for phosphorylase and glycogen synthetase assays were diluted 100fold into the reaction mixture. Changes in enzyme activities were proportional to enzyme concentration and time. Serum potassium was determined by an Instrumentation Laboratory model 143 flame photometer.

UDP-glucose and glucose 1-phosphate were purchased from Boehringer-Mannheim and the $\left[{ }^{14} \mathrm{C}\right]$-labeled compounds were from New England Nuclear. Bovine serum albumin (fraction V) was from Armour.

\section{RESULTS}

Isolated near term fetal monkey livers perfused with high circulating glucose levels did not lower perfusate glucose levels (Figs. 1, 2, and 3); and the addition of insulin to the perfusate did not stimulate net glucose uptake (Figs. 1 and 3). However, when these same livers were perfused with aglycemic medium they did release glucose until circulating levels of $1 \mathrm{mg} / \mathrm{ml}$ were reached (Figs. 2 and 3). The failure of these livers to release greater amounts of glucose was not due to depletion of glycogen reserves (Table 1), and further rapid glucose mobilization could be initiated by the addition of glucagon or cyclic AMP to the perfusate (Fig. 2 ). Liver phosphorylase activity $15 \mathrm{~min}$ after addition of glucagon in the two experiments presented in Figure 2 rose from 4 and 11 to 30 and 34 units/g protein. Therefore, although the isolated fetal monkey liver does not take up appreciable quantities of glucose when exposed to hyperglycemia, it is capable of rapidly mobilizing glucose in response to hypoglycemia or glucagon.

Insulin decreases hepatic glucose output in the adult monkey (7) and in isolated adult rat liver preparations $(11,17,23)$. As seen in Figure 3, this response is present in isolated near term fetal monkey liver. Insulin decreased glucose mobilization in the presence of hypoglycemia.

Table 1 details the corresponding regulation of fetal liver glycogen metabolism as examined by assessing changes in liver glycogen content and the activity of glycogen synthetase for

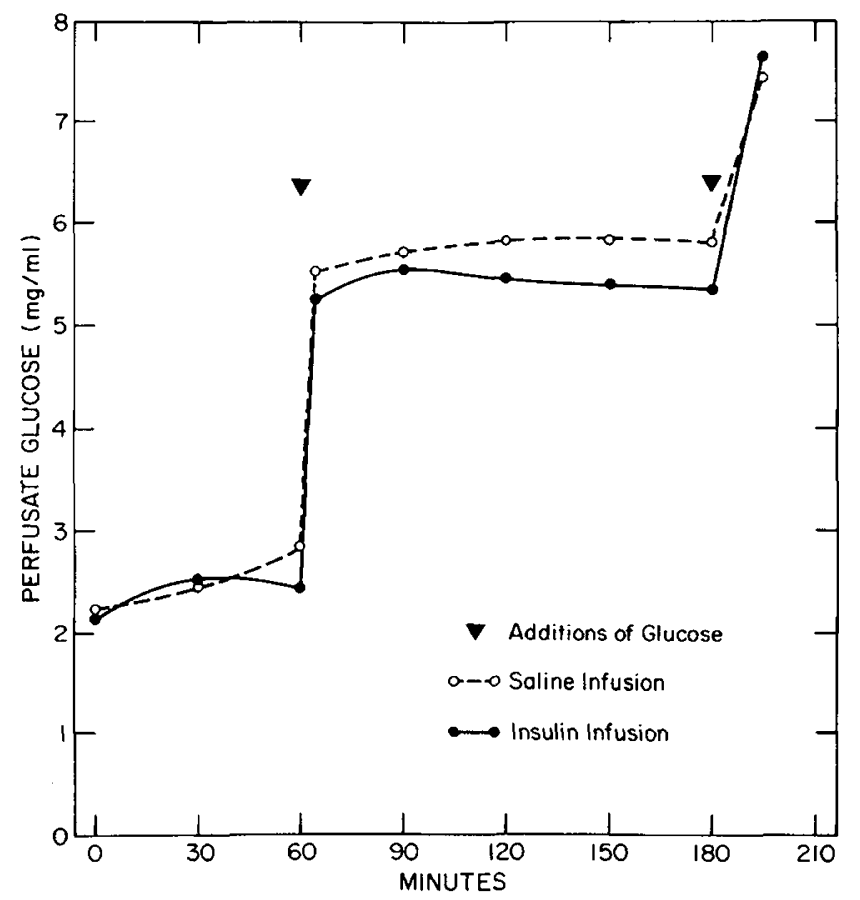

Fig. 1. Responses of two single fetal livers to high levels of glucose and insulin in the recirculating perfusate. Two livers were perfused for $195 \mathrm{~min}$ with additions of glucose being made at 60 and $180 \mathrm{~min}$. Infusions of insulin (Methods) or saline were maintained throughout. At $195 \mathrm{~min}$, glycogen synthetase was $7 \%$ active in the saline-infused liver and $15 \%$ active in the insulin-infused liver. 
experiments depicted in Figures 3 and 4 . In all experiments, decreases in glycogen concentration were observed. An effect of insulin on net changes in liver glycogen concentration was not demonstrated; however, the maximal predicated effect of insulin would be small and within the range of variability in liver glycogen measured (Table 1). With the recirculating liver perfusion system, a stable glucose concentration is achieved within a fixed volume of perfusate $(4 \mathrm{ml} / \mathrm{g} /$ liver $)$. Insulin lowered perfusate glucose by 0.5 $\mathrm{mg} / \mathrm{ml}$ (Fig. 3) which would maximally increase liver glycogen concentration by $0.2 \%$ of liver wt. A mean difference in glycogen levels between the control and insulin-treated groups [Table 1: $(2.4-1.8)-(2.3-1.9)=0.2]$ was not statistically significant. Elevating perfusate glucose concentration did not cause statistically significant activation of glycogen synthetase, whereas the infusion of insulin did. Although there was considerable variation in the activation of glycogen synthetase by insulin, all values obtained after the addition of insulin were higher than any value obtained during control perfusions; the effect of insulin was significant $(P<0.05)$ by the Mann-Whitney test.

The possibility was considered that regulatory mechanisms for storing and releasing hepatic glucose may rapidly change at birth or soon after. This possibility was not supported by studies on 11and 13-day-old neonates (Fig. 4 and Table 1) with the indices

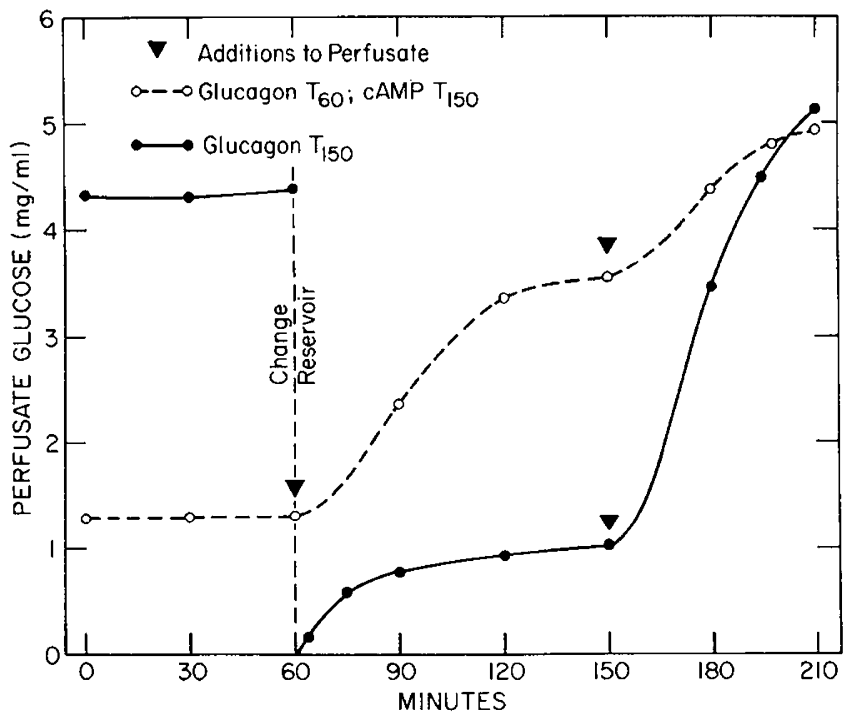

Fig. 2. Responses of fetal liver to hypoglycemia, glucagon, and cyclic AMP. Two single liver perfusions are presented. In one (O- - $-O)$, initially perfused with normoglycemic medium, glucagon and cyclic AMP were added at times indicated at arrows. The second liver (-) was initially perfused with hyperglycemic medium for $60 \mathrm{~min}$, at which time the flow was changed to a second reservoir containing glucose-free medium. After a subsequent $90 \mathrm{~min}$ of perfusion, glucagon was added to the perfusate. tested. Although in these experiments on infants, more glucose was released in the presence of hypoglycemia, rapid hepatic glucose uptake did not occur with hyperglycemia, and glycogen synthetase activity was not altered by changes in circulating glucose concentration.

Livers obtained from near term fetuses of streptozotocin-treated mothers had higher initial glycogen concentrations (Table 1) and also released more glucose when perfused with aglycemic perfusates (Fig. 4). Initial liver glycogen synthetase activity levels were higher, but again they showed no variation with changes in circulating glucose levels (Table 1).

A further assessment of the viability of individual preparations was made by monitoring serum potassium levels. Cellular injury would be associated with failure to maintain a high intracellular potassium concentration and an increase in perfusate potassium would be detected. In addition, insulin increases cellular potassium uptake (17). For each perfusion an average of six half-hourly determinations were used to calculate the mean group behavior (Table 1). In all preparations, serum potassium concentrations were endogenously regulated within a $0.5 \mathrm{mEq} /$ liter range. The

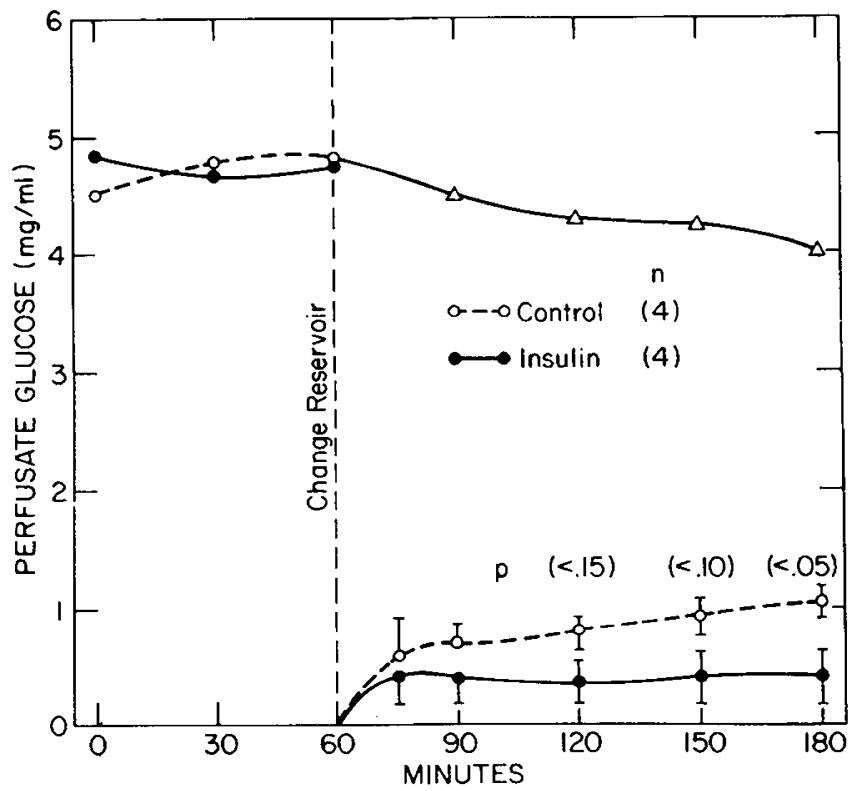

Fig. 3. Inhibition by insulin of hypoglycemic glucose mobilization in term fetal monkey liver. Vertical bars: SEM and $P$ values are for significance of the difference between control- and insulin-infusion responses. In addition to the four control and four insulin infusion experiments, a single liver $(\Delta)$ was examined for control responses to hyperglycemia over the 180 -min experimental period. Liver glycogen, glycogen synthetase, and serum $\mathrm{K}^{+}$data for these experiments are presented in Table 1.

Table 1. Metabolic responses of isolated perfused fetal monkey livers ${ }^{1}$

\begin{tabular}{|c|c|c|c|c|c|c|c|}
\hline \multirow[b]{2}{*}{ Experimental condition } & \multirow[b]{2}{*}{ No. } & \multicolumn{2}{|c|}{ Glycogen, \% liver wt } & \multicolumn{3}{|c|}{ Glycogen synthetase, $\%$ active form } & \multirow{2}{*}{$\begin{array}{l}\text { Serum } \mathrm{K}^{+} \\
\mathrm{mEq} / \text { liter }\end{array}$} \\
\hline & & $t_{0}$ & $t_{180}$ & $\mathrm{t}_{\mathrm{o}}$ & $t_{180}$ & $\mathrm{t}_{210}$ & \\
\hline Insulin infusion & 4 & $2.3 \pm 0.41$ & $1.9 \pm 0.23$ & $5 \pm 1.0$ & $14 \pm 5.4$ & $27 \pm 10.5$ & $4.4 \pm 0.15$ \\
\hline Maternal streptozotocin & 3 & $7.0(5.4-8.9)$ & $6.0(4.0-8.3)$ & $16(21-10)$ & $12(13-9)$ & $9(11-8)$ & $5.6 \pm 0.31$ \\
\hline Neonatal & 2 & $3.8,2.5$ & $2.6,1.6$ & $6.2,4.5$ & $5.0,3.5$ & $5.6,3.8$ & \\
\hline
\end{tabular}

${ }^{1}$ Values are means $\pm \mathrm{SEM}$, means (range), or individual values. Sampling times, $t_{\min }$, correspond to minutes of perfusion in Figures 3 and 4. Corresponding perfusate glucose concentrations are presented in these figures. At $180 \mathrm{~min}$, after sampling, perfusate glucose concentration was raised to $5-6 \mathrm{mg} / \mathrm{ml}$ and perfusion was continued for an additional $30 \mathrm{~min}$ to test for effects of hyperglycemia on glycogen synthetase activity. Total glycogen synthetase activity, which did not vary significantly between the experimental groups, averaged $15 \pm 1.7$ (SEM) units/g protein. Body weights (grams) for the respective groups were control, $395 \pm 31$; insulin infusion, $385 \pm 18$; maaternal streptozotocin, 447 (428-484); and neonatal, 480 and 496. 


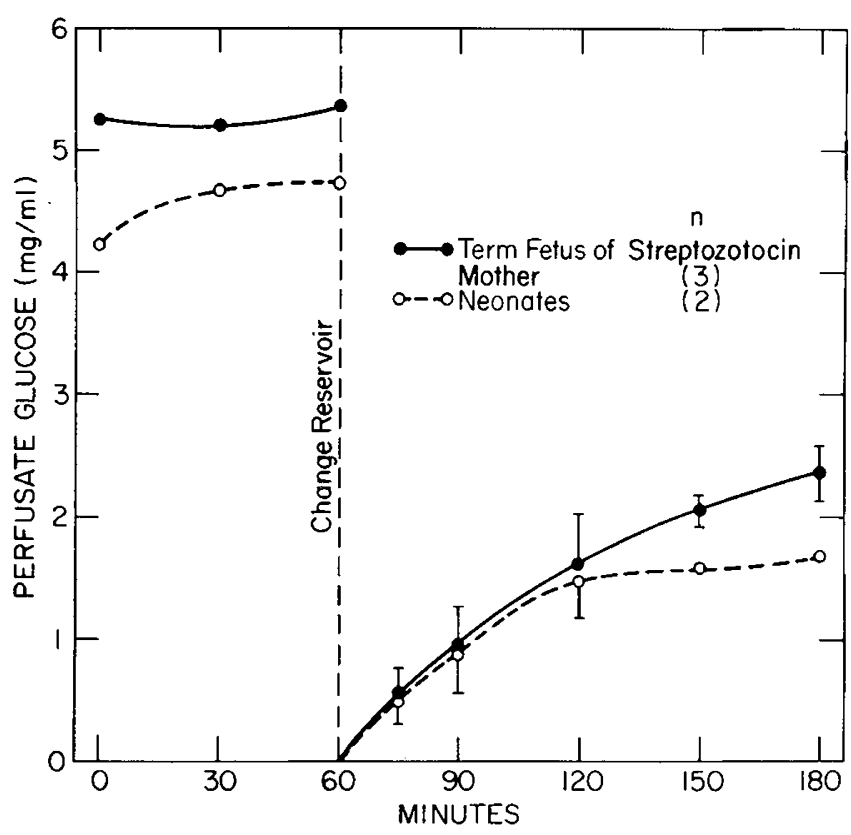

Fig. 4. Responses of three fetal livers of steptozotocin-treated mothers and 11- and 13-day-old neonatal monkey livers to hyper- and hypoglycemia. Vertical bars: SEM. Corresponding glycogen, glycogen synthetase, and serum $\mathrm{K}^{+}$data are presented in Table 1 .

serum potassium was regulated at a lower range in the insulin infusion group when compared with the control series.

\section{DISCUSSION}

The method of perfusion used assessed the behavior of the isolated liver with a defined perfusate of known volume. The perfusate is continuously recirculated and the responses in liver and perfusate composition are determined after experimentally induced changes in the perfusate. Since it is a closed system, in which only the liver is being perfused, the responses obtained are independent of uncontrolled changes in circulating hormones, neural stimuli, and metabolic products from tissues other than the circulating erythrocytes. Net changes in perfusate glucose with time, calculated from the observed changes in perfusate glucose concentration, are used to estimate net hepatic glucose uptake and release.

The isolated term fetal monkey liver perfused by this method released glucose into the perfusate when exposed to glucagon, cyclic AMP, or hypoglycemia. However, it did not take up glucose rapidly nor did it synthesize glycogen when circulating glucose levels in the perfusate were elevated. This inability to store glucose correlated with a failure of hyperglycemia to increase liver glycogen synthetase activity. The present findings in primate fetal liver are analogous to those previously observed with isolated fetal rat liver explants in culture (9). We therefore speculate that direct (glucose concentration-dependent) regulation of glycogen synthetase activity and glycogen synthesis, present in adult mammalian liver $(5,7,16,18-20)$, is not developed during early neonatal life. This may contribute to the low plasma glucose removal rates after bolus glucose injection observed at this time $(2,4,15,20,30)$.

Although the etiologic factors leading to hypoglycemia in the neonatal period are varied, the major compensatory responses for generating circulating glucose are few. Liver glycogen can be mobilized, gluconeogenesis can be stimulated, or food consumption can be increased. Shelly and Neligan (28) provided evidence that liver glycogen is generally depleted when hypoglycemia occurs and discussed the potential importance of liver glycogen reserves in protecting the neonate against hypoglycemia.

Our present study indicates that near term monkey liver does not store glycogen in response to hyperglycemia. We speculate that this inability to store glucose as glycogen makes the neonate vulnerable to the development of glycogen depletion and hypoglycemia during fasting or conditions in which enhanced peripheral glucose uptake or utilization are present. Since hepatic gluconeogenesis in the mammalian neonate is also limited by immaturity of critical enzyme systems (3), the neonate has a limited capacity for synthesizing glucose from protein and consequently is in "double jeopardy" for developing hypoglycemia.

The mechanism by which glucose regulates glycogen synthetase activity in adult liver is unknown. This makes it impossible to relate immaturity of this regulatory response to a particular enzymatic control mechanism. The interconversion of the two forms of glycogen synthetase is controlled by phosphorylation reactions. The cyclic AMP-dependent protein kinase phosphorylates and inactivates the enzyme, and a phosphoprotein phosphatase dephosphorylates and activates the enzyme $(19,31)$. Glucose or a metabolic product of glucose may act at some point in the complex interconversion system $(14,16-19)$, although the precise molecular mechanism is currently unknown. Neonatal liver phosphorylase may be under different regulatory control than the enzyme in adult liver $(8,26,27)$, and this could have secondary effects on glycogen synthetase activation $(8,19)$. Fetal hexokinase isoenzymes, persisting into the neonatal period, do not exhibit a high $K_{m}$ for glucose (3), and this may contribute to differences in formation of glucose metabilites when glucose levels are elevated. Differences in other glycolytic enzymes during this period may also play a role.

Bernard noted over 150 years ago that glycogen was stored in fetal liver. Adrenal glucocorticoids and insulin may be involved in this phenomenon. Glucocorticoids initiate the developmental appearance of liver glycogen synthetase (12), and insulin is capable of activating the enzyme and promoting glycogen synthesis $(9,10)$. The role of insulin was currently assessed by studying its effects on glucose regulation in normal fetal liver and also by studying the functional behavior of livers from fetuses of glucose-intolerant mothers since these fetuses are exposed to chronic hyperinsulinemia in utero (22). Insulin activated glycogen synthetase in the normal fetal primate liver. The livers from fetuses of streptozotocin-treated mothers had increased levels of glycogen and increased glycogen synthetase at the start of perfusion. Insulin decreased glucose mobilization in response to hypoglycemia, as it does in isolated adult rat liver (23). Livers from fetuses of streptozotocin-treated mothers exposed to hypoglycemia in the absense of insulin released more glucose than normal livers. This suggests to us that these livers do not have an intrinsic defect in glucose mobilization. The basis for the increased glucose release in liver from these animals is not known. It was similar in magnitude to that occurring with liver from 2-week-old infants.

The current studies were concerned with defining general features of glucose regulation in isolated perinatal primate liver. It will be important for future studies to consider the sensitivity of these livers to insulin and glucagon since differences in hormone sensitivity during this period may also contribute to neonatal hypoglycemia.

\section{SUMMARY}

Isolated perfused near term fetal and neonatal monkey livers mobilize glucose rapidly in response to glucagon, cyclic AMP, or hypoglycemia but do not take up glucose rapidly, activate glycogen synthetase, or synthesize glycogen in response to hyperglycemia. Insulin inhibits hypoglycemic glucose mobilization and activates glycogen synthetase. The possibility is considered that during the early neonatal period diminished hepatic glycogen synthesis in the presence of hyperglycemia leads to diminished glycogen stores which are necessary for maintaining normoglycemia during fasting and periods of increased glucose utilization. 


\section{REFERENCES AND NOTES}

1. Adam, P. A. J., Kekomaki, M., Rahiala, E. D., and Schwartz, A. L. Autoregulation of glucose production by isolated perfused human liver. Pediat. Res., 6: 396 (1972).

2. Adam, P. A. J., Kornhauser, D., Link, D., and Schwartz, R.: Relationship of insulin secretion rate to blood of glucose concentration in newborn and adult dogs. Biol. Neonate., 14: 194 (1969).

3. Ballard, F. J., In: U. Stave: Physiology of the Perinatal Period, Vol. 1, Chap. 13 pp. 417-440, (Appleton-Century-Crofts, New York, 1970).

4. Bowie, M. D., Mulligan, P. B., and Schwartz, R.: Intravenous glucose tolerance in the normal newborn infant: The effect of double dose of glucose and insulin. Pediatrics, 31: $590-596$ (1963)

5. Buschiazzo, H., Exton, J. H., and Park, C. R.: Effects of glucose on glycogen synthetase, phosphorylase, and glycogen deposition in the perfused rat liver. Proc. Nat. Acad. Sci. U. S. A., 65: 383 (1970).

6. Cornblath, M., and Schwartz, R.: Disorders of Carbohydrate Metabolism in Infancy, pp. 57-81, (W. B. Saunders Co., Philadelphia, 1966).

7. Curnow, R. T., Rayfield, E. J., George, D. T., Zenser, T. V., and De Rubertis, F.: Control of hepatic glycogen metabolism in the rhesus monkey; the effect of glucose, insulin, and glucagon administration. Amer. J. Physiol., 228: 80 (1974).

8. Devos, P., and Hers, H.-G.: Glycogen metabolism in the liver of the foetal rat. Biochem. J., 140: 331 (1974).

9. Eisen, H. J., Glinsmann, W. H., and Sherline, P.: Effect of insulin on glycogen synthesis in fetal rat liver in organ culture. Endocrinology, 92: 584 (1973).

10. Eisen, H. J., Goldfine, I. D., and Glinsmann, W. H.: Regulation of hepatic glycogen synthesis during fetal development: Roles of hydrocortisone, insulin, and insulin receptor. Proc. Nat. Acad. Sci. U. S. A., 70: 3454 (1973).

11. Exton, J. H., Lewis, S. B., Ho, R. J., and Park, C. R.: The role of cyclic AMP in the control of hepatic glucose production by glucagon and insulin. Advan. Cyclic Nucl. Res., 1: 91 (1972).

12. Fleishman, A. R., Lerman, S., Oaks, G. K., Epstein, M. F., Chez, R. A., and Mintz, D. H.: Perinatal primate parathyroid hormone metabolism. Biol. Neonate, 27: 40 (1975).

13. Genser, G., Lundquist, I., and Nilsson, E.: Glycogenolytic activity in the liver of the human fetus. Biol. Neonate, 19: 1 (1971)

14. Gilboe, D. P., and Nuttal F. Q.: The regulation of liver glycogen synthetase by ATP and glucose. Biochem. Biophys. Res. Commun., J3: 164 (1973).

15. Gladtke, E., Dost, F. H., and van Hattingberg, M.: Glucose imsatz bei Neugeborenen. Deut. Med. Wschr., 93: 684 (1968).

16. Glinsmann, W. H., Hern, E. P., and Lynch, A.: Intrinsic regulation of glucose output by rat liver. Amer. J. Physiol., 216: 698 (1969).
17. Glinsmann, W. H., and Mortimore, G. E.: Influence of glucagon and 3',5'-AMP on insulin responsiveness of the perfused rat liver. Amer. J. Physiol., 215: 553 (1968).

18. Glinsmann, W., Pauk, G., and Hern, E.: Control of rat liver glycogen synthetase and phosphorylase activities by glucose. Biochem. Biophys. Res. Commun., 39: 774 (1970)

19. Hers, H.-G., Stahlmans, W., DeWolf, H., Lalous, M., and Hue, L.: The control of glycogen metabolism in liver. In: E. H. Fisher: Metabolic Interconversion of Enzymes, pp. 89-98, Springer-Verlag, Berlin, (1973).

20. King, K. C., Adam, P. A. J., Clemente, G. A., and Schwartz, R.: Infants of diabetic mothers: Attenuated glucose uptake without hyperinsulinemia during continuous glucose infusion. Pediatrics, 44: 381 (1969).

21. McCann, M. L., Chen, C. H., Katigbak, E. B., Kotchen, J. M., Likly, B. F., and Schwartz, R.: Effects of fructose on hypoglycosemia in infants of diabetic mothers. New Engl. J. Med., 275: 1 (1966).

22. Mintz, D. H., Chez, R. A., and Hutchinson, D. L.: Subhuman primate pregnancy; complications by streptozotocin-induced diabetes mellitus. J. Clin. Invest., 51: 837 (1972).

23. Mortimore, G. E., King, E., Jr., Mondon, C. E., and Glinsmann, W. H.: Effects of insulin on net carbohydrate alterations in perfused rat liver. Amer. J. Physiol., 212: 179 (1967).

24. Pennoyer, M. M., and Hartman, A. F.: Management of infants born of diabetic mothers. Postgrad. Med., 18: 199 (1955).

25. Reardon, H. S.: In: Infants of Diabetic Mothers: Report of the thirty-first Ross Conference on Pediatric Research, pp. 72-77, (Ross Laboratories, Columbus, Ohio, 1958).

26. Schwartz, A. L., Ph.D. thesis. Hormonal regulation of glucose production in human fetal liver (Case Western Reserve University, 1974).

27. Schwartz, A. L., and Rall, T. W.: Hormonal regulation of glycogen metabolism in neonatal rat liver. Biochem. J., /34: 985 (1973).

28. Shelley, H. J., and Neligan, G. A.: Neonatal hypoglycemia. Brit. Med. Bull., 22: 34 (1966).

29. Sherline, P., Eisen, H., and Glinsmann, W.: Acute hormonal regulation of cyclic AMP content and glycogen phosphorylase activity in fetal liver in organ culture. Endocrinology, 94: 935 (1974).

30. Varma, S., Nickerson, H., Cowen, J. S., and Hetenyi, G., Jr.: Homeostatic responses to glucose loading in newborn and young dogs. Metabolism, 22: 1367 (1973).

31. Zieve, F. J., and Glinsmann, W. H.: Activation of glycogen synthetase and inactivation of phosphorylase kinase by the same phosphoprotein phosphatase. Biochem. Biophys. Res. Commun., 50: 872 (1973).

32. Requests for reprints should be addressed to: W. H. Glinsmann, National Institutes of Health, Bldg. 6, Rm. 314, Bethesda, Md. 20014 (USA)

33. Accepted for publication, March 26, 1975.

Printed in U.S.A.

Pediat. Res. 9: 604-609 (1975)

Capillary blood

hypothyroidism, congenital thyroxine $\left(\mathrm{T}_{4}\right)$

\title{
Thyroxine $\left(\mathrm{T}_{4}\right)$ Immunoassay Using Filter Paper Blood Samples for Screening of Neonates for Hypothyroidism
}

\author{
P. REED LARSEN (18) AND KATHY BROSKIN
}

Division of Endocrinology and Metabolism, Department of Medicine, University of Pittsburgh School of Medicine, Pittsburgh, Pennsylvania, USA

Extract

A rapid, sensititive radioimmunoassay for thyroxine $\left(T_{4}\right)$ is described which requires a specimen of dried blood on filter paper. One milliliter of glycine-acetate buffer containing anti- $\mathrm{T}_{4}$ antibody, tracer $T_{4}$, and sodium salicylate is added to a tube containing a $1 / 8$-inch dot of the filter paper specimen. After incubation overnight, bound and free hormone are separated by addition of dextran-coated charcoal. Quantitation is obtained using a standard curve prepared from dots of dried blood samples with known $T_{4}$ content. The dot remains in the solution throughout the procedure. Recovery of $\mathrm{T}_{4}$ is $95 \%$ and intra- and interassay coefficients of variation are both less than $10 \%$. The mean $T_{4}$ content of 983 samples from 3-day-old infants was $189 \pm 48 \mathrm{pg} T_{4} /$ dot (mean SD). This corresponds to the $T_{4}$ in $1.5 \mu \mathrm{l}$ plasma, and thus the estimated plasma $T_{4}$ in these infants is $12.6 \pm 3.2 \mu \mathrm{g} \mathrm{T}_{4} / 100$ ml. Nine neonates had repeated samples in which the $T_{4}$ content was lower than 2 SD below the mean. All of these infants had normal cord thyroid-stimulating hormone (TSH) concentrations and thus presumably do not have primary hypothyroidism. The method 